\title{
Low diagnostic value of respiratory impedance measurements in children
}

\author{
C.E.J. Cuijpers*, G.J. Wesseling**, A.G.H. Kessels*, G.M.H. Swaen*, \\ P.L.J.M. Mertens ${ }^{+}$, M.E. de Kok*, J. Broer ${ }^{++}$, F. Sturmans*, E.F.M. Wouters**
}

Low diagnostic value of respiratory impedance measurements in children. C.E.J.Cuijpers, G.J. Wesseling, A.G.H. Kessels, G.M.H. Swaen, P.L.J.M. Mertens, M.E. de Kok, J. Broer, F. Sturmans, E.F.M. Wouters. (CERS Journals Ltd 1997.

ABSTRACT: The aim of this study was to determine whether impedance values in children with various chronic respiratory complaints differed from those observed in symptom-free children.

Respiratory impedance was measured using the forced oscillation technique in 1,776 Dutch children aged 6-12 yrs. In addition to the commonly used parameters of resistance and reactance, further impedance parameters were obtained by using linear and quadratic regression to describe individual resistance and reactance curves as a function of frequency. Furthermore, the diagnostic value of the individual impedance parameters was evaluated by means of receiver operator characteristic (ROC) curves.

Statistically significant differences in impedance values were found in girls with symptoms suggesting asthma compared to symptom-free girls, but not in boys. In children with chronic cough, impedance was not significantly different from the values of symptom-free children. The results obtained by the additional impedance parameters were comparable to those of the commonly used measures.

We conclude that the diagnostic value of the impedance parameters appeared to be low, as no cut-off points were found to discriminate clearly between symptomatic and symptom-free children. These findings may reflect absence of functional abnormalities in symptomatic children at this age. Eur Respir J., 1997; 10: 88-93.

Using the technique of forced oscillations (FOT), the mechanical properties and the frequency-dependent behaviour of the respiratory system can be determined. The FOT yields values for the total resistance $(R \mathrm{rs})$ and reactance $(X \mathrm{rs})$ of the respiratory system. The measurements are noninvasive, independent of effort, and require little or no co-operation from the subject. Therefore, they can be performed easily, especially in young children. Respiratory impedance has been studied in adults [1-4], as well as in children [5-13], in various clinical and epidemiological settings. Recent reports have suggested that the technique may be a suitable tool for epidemiological studies [14, 15].

Recently, we have reported resistance and reactance values at 8 and $28 \mathrm{~Hz}$, in 371 normal children aged 6-12 yrs [16]. All impedance parameters were significantly related to height and varied between sexes. Negative frequency dependence of resistance between 8-28 $\mathrm{Hz}$ was a common finding, most pronounced in (young) boys. Furthermore, we have reported differences in impedance values between children with $(n=110)$ and without $(n=360)$ asthma-like symptoms [17]. The analysis of these was restricted to mean values at single frequencies in the frequency range $8-28 \mathrm{~Hz}$. At present, more information on the impedance versus frequency curves $(4-48 \mathrm{~Hz})$ can be obtained, due to further computerization of the impedance data.
Depts of *Epidemiology and **Pulmonology, University of Maastricht, The Netherlands. +Dept of Public Health Roermond, and ${ }^{++}$Dept of Public Health Groningen, Regional Health Services, The Netherlands.

Correspondence: G.J. Wesseling

Dept of Pulmonology

University of Maastricht

P.O. Box 5800

6200 AZ Maastricht

The Netherlands

Keywords: Asthma

children

diagnostic value

forced oscillation technique

respiratory impedance

Received: October 101994

Accepted after revision August 161996
The aims of the present study were to analyse the relationship between various respiratory symptoms, such as chronic cough or asthma, and the frequency dependence of the respiratory impedance compared with those of symptom-free children in a large cohort of children. Using linear and quadratic regressions, individual resistance and reactance curves were described as a function of frequency $(f)$, and the diagnostic value of the different impedance measures was evaluated by means of receiver operator characteristic (ROC) curves. The analyses were performed for boys and girls separately.

\section{Methods}

We conducted a survey on respiratory health in 1,968 primary school children in two different regions of the Netherlands. The prevalence of respiratory symptoms was evaluated using a written questionnaire, completed by the parents of the children. Respiratory impedance measurements were performed using a FOT [18]. Data collection was carried out by trained technicians, at the same time (between March and May 1993) in both regions, with similar methods and according to a standard protocol. 


\section{Subjects}

In co-operation with two local health services, 1,968 children were approached, from 19 primary schools: 1,281 children living in the south of the Netherlands (Limburg) and 687 children living in the north of the Netherlands (Groningen).

Informed consent to examine the children was obtained from the parents of 1,226 (96\%) children in Limburg and from the parents of $658(96 \%)$ children in Groningen, resulting in a total response of 1,884 (96\%) children.

\section{The questionnaire}

The prevalence of respiratory symptoms was evaluated by means of a written questionnaire, completed by the parents of the children. The questionnaire is a Dutch version of the children's questionnaire of the World Health Organisation (WHO) published by FLOREY and LEEDER [19], (see Appendix). The reproducibility of the answers of the Dutch questionnaire has been found to range from good to very good for almost all questions, especially for the questions on wheeze, and shortness of breath with wheeze, with Cohen's kappa values ranging 0.600.96 . The reproducibility of (chronic) cough was less $(\mathrm{kappa}=0.28)[20]$. The questionnaires were distributed in the participating schools 2 weeks before the team who performed the lung function measurements visited the school. At the time of the lung function measurements the questionnaires were collected.

\section{The forced oscillation technique}

The mechanical characteristics of the respiratory system were measured using the technique of forced oscillations, according to the method described by LÀNDSÉR et al. [21]. The technique has been described in detail previously [22]. The protocol was similar to that used in earlier studies $[16,17]$. Briefly, a pseudorandom noise signal, consisting of sinusoidal pressure oscillations, containing all harmonics of $2 \mathrm{~Hz}$ up to $48 \mathrm{~Hz}$, was applied at the mouth of the seated child. During the measurements the child breathed quietly and wore a noseclip. To eliminate the effect of the upper airway artifact [23], the cheeks and the floor of the mouth were firmly supported with the hands of the investigator or by the child. Mouth pressure and mouth flow were measured with identical differential pressure transducers (Validyne MP45®), and fed into a Fourier analyser, dividing pressure by flow. The system calculates an impedance value for each of the frequencies investigated. The impedance is partitioned into a real part, $R$ rs, and an imaginary part or reactance, $X \mathrm{rs}$. $R$ rs, is the equivalent of the total resistance in a resistance-inductancecapacitance (R-L-C) circuit. $X$ rs depends on the elastic and inertial properties of the respiratory system. The frequency at which $X$ rs equals zero is called the resonant frequency $(f 0)$. To evaluate the reliability of the measurement, a coherence function is estimated at each frequency. This indicates the amount of noise generated by the child's spontaneous breathing, present in the signals measured [24].
Each child performed at least five valid impedance measurements, according to the recommendations which have recently been set up by an international working group on standardization of impedance measurements in children [18].

\section{Analyses}

Based on the information obtained by the questionnaires, four groups of children were distinguished: 1) children who were free from past and present (chronic) respiratory symptoms ("symptom free"); 2) children who reported chronic cough (cough for at least 3 months a year) but no other (chronic) respiratory symptoms ("chronic cough"); 3) children who reported at least two of the four asthma-like symptoms (chronic cough, shortness of breath during exercise, wheeze, and attacks of shortness of breath with wheeze) in the previous year, to include wheeze or attacks of shortness of breath with wheeze ("asthma-like symptoms"); and 4) children with one or more past or present respiratory symptoms, but who did not meet the inclusion criteria of Group 2 or 3 ("rest group" or Group 4) (see Appendix).

The following parameters were chosen to characterize the curves: $\beta 1, \alpha 1, \gamma \mathrm{q}, \beta \mathrm{q}$ and $\alpha \mathrm{q}$, both for resistance $(R \mathrm{rs})$ and reactance curves $(X \mathrm{rs})$. For each child, linear regression (l) curves $(\mathrm{Y}=\beta 1 \mathrm{l} f+\alpha \mathrm{l})$ over the frequency ranges $4-48 \mathrm{~Hz}, 4-12 \mathrm{~Hz}$ and $8-28 \mathrm{~Hz}$, and quadratic regressions (q) ( $\left.\mathrm{Y}=\gamma_{\mathrm{q}} f^{2}+\beta \mathrm{q}, f+\alpha \mathrm{q}\right)$ over the frequency range $4-48 \mathrm{~Hz}$ were fitted to describe respiratory resistance and reactance as a function of frequency.

The curves were characterized by the following parameters: $\beta 1, R, \alpha 1, R, \gamma \mathrm{q}, R, \beta \mathrm{q}, R, \alpha \mathrm{q}, R, \beta 1, X, \alpha 1, X, \gamma \mathrm{q}, X, \beta \mathrm{q}, X$ and $\alpha \mathrm{q}, X$. Differences in these curve characteristics and in the "on-line" impedance parameters $(R \mathrm{rs} 8, X \mathrm{rs} 8, f 0$ and frequency dependence of resistance (FD), defined as $R_{\mathrm{rs}} 28$ minus $R$ rs 28 divided by 20 ), between symptom-free children and children from the different symptom-groups were tested using unpaired t-tests (crude data) and multiple linear regression analyses. In the latter, differences in impedance values between the groups were adjusted for age, height, weight and gender.

The relationship between the sensitivity and specificity for possible cut-off points to discriminate between the various symptom groups was investigated with the help of receiver operator characteristic (ROC) curves. In a ROC curve the sensitivity of an index is plotted by the complement of the specificity [25]. ROC curves were constructed for all impedance parameters investigated. Each symptom subgroup (chronic cough, asthmalike symptoms, and rest group) was compared separately to the symptom-free group. For all children, curve parameters of the linear- and quadratic-regressions over the frequency range $4-48 \mathrm{~Hz}$ were investigated, and those of the linear curves for the ranges $8-28 \mathrm{~Hz}$, and 4-12 Hz. Finally, the children were divided by gender (boys, girls) and height (four categories: <120, 120-139, 140159 , and $\geq 160 \mathrm{~cm}$ ), and ROC curves were constructed again.

The analyses were performed using Statistical Package for the Social Sciences (SPSS)-X statistical [26]. A p-value of less than 0.05 was considered significant. 


\section{Results}

\section{Response}

Completed questionnaires were returned by 1,885 (99\%) parents. Valid impedance measurements of 1,792 (91\%) children were obtained. The combination of a fully completed questionnaire and valid impedance measurements was available for 1,776 (90\%) children. In table 1 , the numbers of children distributed over the four symptom groups are presented. The distribution was almost similar for boys and for girls. Nine hundred and nineteen children were free of any past or present respiratory symptoms and were, thus, considered healthy. Symptoms of asthma were found in 198 (11\%) children, somewhat more in boys $(12 \%)$ than in girls $(10 \%)$.

\section{Impedance values}

The impedance values in the children with no chronic respiratory symptoms showed negative frequency dependence of resistance, i.e. a decrease in resistance with increasing frequency, negative reactance values at lower frequencies, and resonant frequencies ranging from $13.2 \pm 6.1 \mathrm{~Hz}$ in smaller boys and from $13.4 \pm 5.5 \mathrm{~Hz}$ in smaller girls to $9.3 \pm 4.7 \mathrm{~Hz}$ and $9.5 \pm 3.2 \mathrm{~Hz}$, respectively, in boys and girls over $150 \mathrm{~cm}$ (data not shown).

In table 2 , the differences in impedance values between children without respiratory symptoms and children with symptoms of asthma are summarized. For girls with asthma-like symptoms, compared to symptom-free girls, statistically significant differences were observed for almost all impedance parameters investigated (table 2). The results from the t-tests (crude data) and the regression analysis (adjusted data), in which impedance values between the different symptom-groups and the symptom-free children were compared, showed good agreement and the results for the parameters of the linear and quadratic curves were quite comparable, and of a similar magnitude and direction to those obtained by the more commonly used "on-line" parameters $(R \mathrm{rs} 8, X \mathrm{rs} 8, \mathrm{FD}$ and $f 0)$. The linear curve characteristics of the subsections $4-12 \mathrm{~Hz}$ and $8-28 \mathrm{~Hz}$ were also comparable to those over the total frequency range $(4-48 \mathrm{~Hz})$, only the difference in $\beta 1, R$ for both frequency ranges was no longer significant. In contrast, small differences (t-tests) between boys with and without asthma-like symptoms were observed for $\alpha 1, R, 4-48$ and $\alpha 1, R, 4-12$, only $(\mathrm{p} \leq 0.10)$. After adjusting the data by regression analysis, these differences disappeared. Although the differ-
Table 2. - Difference in impedance parameters between "asthmatic" and symptom-free children, boys and girls separately

\begin{tabular}{lccc}
\hline Parameters & Gender & $\Delta$ crude & $\Delta$ adjusted \\
\hline$\beta 1, R$ & $\mathrm{M}$ & -0.006 & -0.004 \\
& $\mathrm{~F}$ & $-0.025^{* * *}$ & $-0.024^{* * *}$ \\
$\alpha 1, R$ & $\mathrm{M}$ & $0.378^{+}$ & 0.242 \\
& $\mathrm{~F}$ & $1.146^{* * *}$ & $1.078^{* * *}$ \\
$\beta 1, X$ & $\mathrm{M}$ & 0.000 & -0.001 \\
& $\mathrm{~F}$ & -0.001 & -0.001 \\
$\alpha 1, X$ & $\mathrm{M}$ & -0.093 & 0.007 \\
& $\mathrm{~F}$ & $-0.440^{*}$ & $-0.384^{*}$ \\
$R \mathrm{rs} 8$ & $\mathrm{M}$ & 0.222 & 0.042 \\
& $\mathrm{~F}$ & $0.723^{* * *}$ & $0.622^{* * *}$ \\
$X \mathrm{rs} 8$ & $\mathrm{M}$ & -0.055 & 0.034 \\
& $\mathrm{~F}$ & $-0.473^{* *}$ & $-0.428^{* * *}$ \\
$\mathrm{FD}$ & $\mathrm{M}$ & 0.002 & 0.006 \\
& $\mathrm{~F}$ & $-0.023^{* * *}$ & $-0.020^{* *}$ \\
$f 0$ & $\mathrm{M}$ & 0.821 & 0.318 \\
& $\mathrm{~F}$ & $1.920^{*}$ & $1.642^{* *}$ \\
$\beta \mathrm{q}, R$ & $\mathrm{M}$ & -0.002 & $2.50 \mathrm{E}-04$ \\
& $\mathrm{~F}$ & $-0.16^{* * *}$ & $-0.015^{* * *}$ \\
$\alpha \mathrm{q}, R$ & $\mathrm{M}$ & 0.160 & 0.059 \\
& $\mathrm{~F}$ & $0.310^{*}$ & $0.261^{*}$ \\
$\alpha \mathrm{q}, X$ & $\mathrm{~F}$ & $-0.396^{* * *}$ & $-0.354^{* * *}$ \\
\hline
\end{tabular}

M: male; F: female; 1: linear regression; q: quadratic; $\alpha$ : intercept; $\beta$ : coefficient first order term; $R$ : resistance; $X$ : reactance; rs: respiratory system; FD: frequency dependence of resistance; $f 0$ : resonant frequency. ${ }^{*}: \mathrm{p}<0.05 ;{ }^{* *}: \mathrm{p}<0.01 ; * *$ : $\mathrm{p}<0.001)$.

ences between boys with asthma-like symptoms and symptom-free boys were smaller and not significant, in general the direction of the difference was comparable to that observed in girls (table 2).

To investigate whether differences between "asthmatic" and symptom-free children differ between boys and girls, interaction-terms (I) were entered into the regression analysis. For almost all impedance parameters investigated statistically significant interaction terms were found between symptom status and gender.

For the children with chronic cough and the children with "rest" symptoms small and mainly nonsignificant differences were observed when the impedance values were compared with those of the symptom-free children (data not shown).

\section{Diagnostic value of the FOT}

Figure 1 presents one of the ROC curves: $\beta 1, R$ over the whole frequency range $(4-48 \mathrm{~Hz})$ for the total group of children investigated. This example was arbitrarily

Table 1. - Numbers of children in the different symptom groups: symptom-free, chronic cough, asthma-like symptoms and rest

\begin{tabular}{lccccc}
\hline Gender & $\begin{array}{c}\text { Symptom- } \\
\text { free }\end{array}$ & $\begin{array}{c}\text { Chronic } \\
\text { cough }\end{array}$ & $\begin{array}{c}\text { Asthma-like } \\
\text { symptoms }\end{array}$ & Rest group & Total \\
\hline Male & $472(52)$ & $41(5)$ & $110(12)$ & $283(31)$ & $906(100)$ \\
Female & $447(52)$ & $37(4)$ & $88(10)$ & $298(34)$ & $870(100)$ \\
\hline Total & $919(52)$ & $78(4)$ & $198(11)$ & $581(33)$ & $1776(100)$ \\
\hline
\end{tabular}

Absolute values are presented, with percentages in parenthesis. 


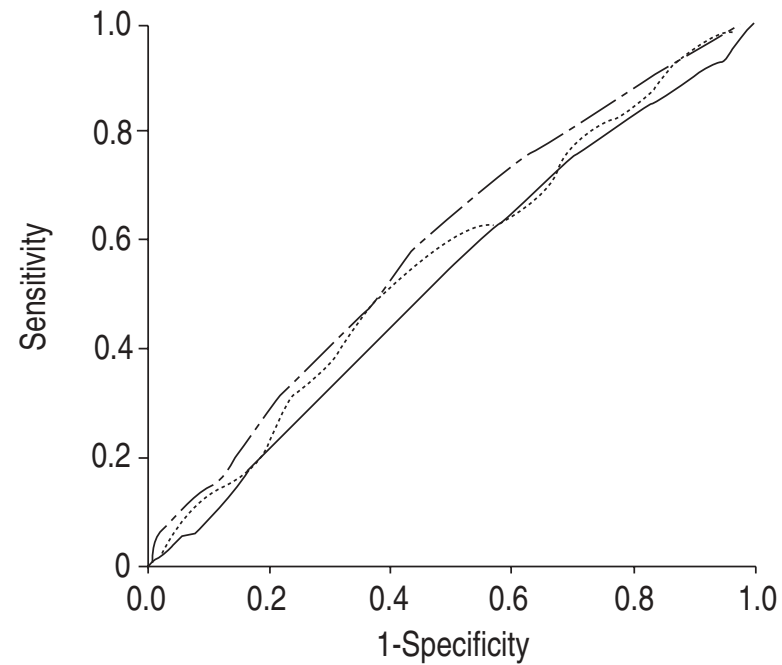

Fig. 1. - Received operator characteristic (ROC) curve for $\beta \mathrm{l}, R$ over the whole frequency range $(4-48 \mathrm{~Hz})$ for children with chronic cough ( $(-)$, asthma-like symptoms (-.-.-.) or "rest" symptoms (……........) (Group IV) were compared separately to the symptom-free children. 1: linear regression; $R$ : resistance; $\beta$ : coefficient first order term.

chosen. Ideally, the ROC curve should approach the upper left hand corner $($ sensitivity $(\mathrm{Se})=$ specificity $(\mathrm{Sp})$ $=100 \%$ ). The curve is around the diagonal, which means that for this parameter no cut-off point can be found which discriminates between symptom-free children and children with (chronic) respiratory symptoms. This can also be demonstrated by the frequency distribution presented in figure 2, which shows large overlap for the different groups of children. Again the example is arbitrarily chosen, since all parameters from the linear regressions, in all three frequency ranges, and the quadratic regressions as well as for $R \mathrm{rs} 8, X \mathrm{rs} 8, \mathrm{FD}$ and $f 0$ showed similar results. When the total group was stratified for gender and height (four categories), again no cut-off points with clear diagnostic value for any of the different symptom groups were found (data not shown).

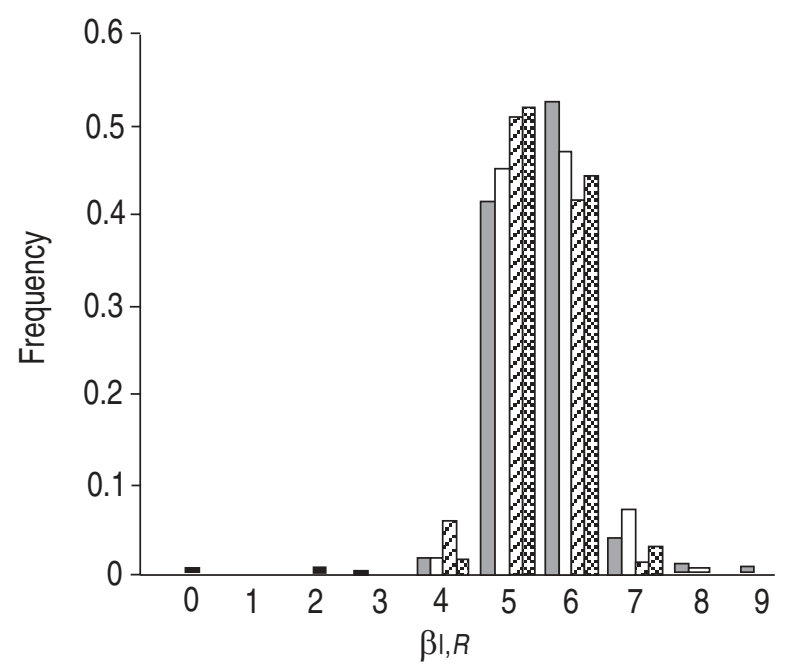

Fig. 2. - Frequency distribution of $\beta 1, R$ (4-48 Hz), for symptomfree children ( $\square$ ), children with chronic cough $(\square)$, asthma-like symptoms ( $\square$ ) or "rest" symptoms ( $\square$ ) (Group IV). $\beta$ : coefficient first order term; 1 : linear regression; $R$ : resistance.

\section{Discussion}

In the present study, respiratory impedance was studied in 1,776 Dutch children, aged 6-12 yrs. Of these children, $919(52 \%)$ were free from any past or present respiratory symptoms, $78(4 \%)$ were reported to suffer from chronic cough, 198 (11\%) were found to have symptoms suggesting asthma, and $581(33 \%)$ had one or more past or present respiratory symptoms, excluding chronic cough and asthma. Impedance values found in the symptom-free children were similar to those reported previously $[8-10,16]$, and were considered normal. In girls with symptoms of asthma but not in boys, statistically significant differences in almost all impedance parameters investigated were found compared with symptom-free children. Impedance values in the other symptom groups were not different from those of the symptom-free children. This suggests that only asthmalike symptoms related to changes in the mechanical characteristics of the respiratory system. In absolute terms, the observed effects were small, but they had a plausible direction and were comparable to our previous findings [17]. The differences in boys were comparable to those found in girls, but smaller and not statistically significant. A gender difference in respiratory impedance outcomes has been reported previously $[5,7,16]$. No clear differences were observed between symptom-free girls and symptom-free boys.

In the impedance analyses, the curve characteristics $(\gamma, \beta$ and $\alpha)$ were studied in addition to the commonly used "on-line" parameters $R \mathrm{rs} 8, X \mathrm{rs} 8, f 0$ and FD. The results of all parameters investigated were quite comparable and had a plausible direction. In particular, the magnitude and direction of the differences for $\beta$ and $\alpha$ of the linear $R$ rs curve (4-48 Hz) compared well with our previous findings. No additional information was obtained by the linear curves considering the subsections $4-12 \mathrm{~Hz}$ and $8-28 \mathrm{~Hz}$. Using quadratic regressions to describe resistance and reactance curves as a function of frequency was of no additional value when compared to the linear curves.

The diagnostic value of the impedance parameters analysed with ROC curves was found to be low. No clear cut-off points to discriminate between symptomatic and symptom-free children were observed. Stratification for height and gender did not fundamentally change the results. Even though statistically significant, albeit small, differences in impedance values were found, no cut-off point was identified for any of the impedance parameters with acceptable values of sensitivity and specificity, which would discriminate between symptom-free children and children with chronic cough, asthma-like symptoms, or the rest-group. These results did not change when the analyses were stratified for height (four categories) and gender.

A possible explanation for these results is that in crosssectional measurements the FOT is not sensitive enough to identify children with self-reported respiratory symptoms. To define the symptom groups in this study, we used reported symptoms in the previous year (12 month prevalence) and compared them with an impedance measurement at a single moment, when the children were at school. This may have resulted in a certain bias, since the children with the most severe abnormalities at the time 
of the impedances measurements may have been kept away from school, thus diminishing the differences between the groups. Furthermore, no information was available on the severity of the symptoms or on possible use of antiasthma medication.

In an earlier study [17], we showed that in children diagnosed as having asthma by a doctor and using antiasthma medication lung function abnormalities were less pronounced than in those children with symptoms suggesting asthma but not on antiasthma medication. This implies that the use of medication may have obscured differences in the present study. Also, one should bear in mind that the reproducibility of the answers to the questions regarding chronic cough in the questionnaire is known to be poor [20]. Alternatively, as suggested by previous studies [27-29], if the forced oscillation technique has the diagnostic sensitivity to detect airway abnormalities, the absence of differences in impedance between children with and children without respiratory complaints may indeed reflect absence of functional abnormalities.

In conclusion, we found the diagnostic value of the impedance parameters to be low. The use of linear and quadratic regressions, to describe individual resistance and reactance curves as a function of frequency, did not give additional information on the discriminative abilities of the forced oscillation technique as compared to simpler measures at single frequencies. However, lack of measurable functional differences between symptomatic and symptom-free children at this age may explain the observations.

\section{Appendix}

The Dutch version of the children's version of the WHO questionnaire [19]:

4. Did your child cough, usually in the morning, during the autumn and winter season?

5. Did your child cough, usually during daytime or at night, during the autumn and winter season?

6. Did your child cough on most days, for at least 3 months a year?

7. Has your child ever been troubled by shortness of breath when playing outside or climbing the stairs?

8. Has your child been troubled by shortness of breath when playing outside or climbing the stairs, in the previous year?

9. Has your child's chest ever sounded wheezy?

10. Has your child's chest sounded wheezy, in the previous year?

11. Has your child ever had attacks of shortness of breath with wheeze?

12. Has your child had attacks of shortness of breath with wheeze, in the previous year?

Symptom free: children who are free from all above described past or present chronic respiratory symptoms.

Chronic cough: children who report chronic cough (6), but none of the other chronic respiratory symptoms.

Asthma: children who report at least two of the four asthma-like symptoms $(6,8$, 10 and 12) in the previous year, to include 10 or 12 .
Rest group:

children who report one or more past or present respiratory symptoms (4-12) but who do not meet the inclusion criteria for chronic cough or asthma (Group 4).

\begin{abstract}
Acknowledgements: The authors wish to thank the teachers of the co-operating schools and the children and their parents for participating in the study. They thank J. Slangen for his valuable contribution to the statistical analysis and R. Cardynaals for his help in handling the enormous impedance data files. This study was conducted in a successful collaboration between the Departments of Public Health, Regional Services in Roermond and Groningen, and the University of Maastricht.
\end{abstract}

\section{References}

1. Van Noord JA, Wellens W, Clarysse I, Cauberghs M, Van de Woestijne KP, Demedts M. Total respiratory resistance and reactance in patients with asthma, chronic bronchitis and emphysema. Am Rev Respir Dis 1991; 143: 922-927.

2. Wesseling GJ, Vanderhoven-Augustin IML, Wouters EFM. Forced oscillation technique and spirometry in cold air provocation tests. Thorax 1993; 48: 254-259.

3. Clément J, Làndsér FJ, Van de Woestijne KP. Total resistance and reactance in patients with respiratory complaints with and without airway obstruction. Chest 1983; 83: 215-220.

4. Chalker RB, Celli BR, Habib RH, Jackson AC. Respiratory input impedance from 4 to $256 \mathrm{~Hz}$ in normals and chronic airflow obstruction: comparisons and correlations with spirometry. Am Rev Respir Dis 1992; 146: 570-576.

5. Wesseling GJ, Quaedvlieg M, Wouters EFM. Inhaled budesonide in chronic bronchitis: effects on respiratory impedance. Eur Respir J 1991; 4: 1101-1105.

6. Clément J, Dumoulin B, Gubbelmans R, Hendriks KP, Woestijne van de KP. Reference values of total respiratory resistance and reactance between 4 and $26 \mathrm{~Hz}$ in children and adolescents aged 4-20 years. Bull Eur Physiopathol Respir 1987; 23: 441-448.

7. Duiverman EJ, Clément J, Woestijne van de KP, Neijens HJ, Bergh van den ACM, Kerrebijn KF. Forced oscillation technique: reference values for resistance and reactance over a frequency spectrum of $2-26 \mathrm{~Hz}$ in healthy children aged 2.3-2.5 years. Bull Eur Physiopathol Respir 1985; 21: 171-178.

8. Hantos Z, Daróczy B, Gyurkovits K. Total respiratory impedance in healthy children. Pediatr Pulmonol 1985; 1: 91-98.

9. Hordvik NL, König P, Morris DA, Kreutz C, Pimmel RL. Normal values for forced oscillatory respiratory resistance in children. Pediatr Pulmonol 1985; 1: 145-148.

10. Peslin R, Gallina C, Teculescu D, Pham QT. Respiratory input and transfer impedances in children 9-13 years old. Bull Eur Physiopathol Respir 1987; 23: 107112.

11. Solymar L, Aronsson PH, Bake B, Bjure J. Respiratory resistance and impedance magnitude in healthy children aged 2-18 years. Pediatr Pulmonol 1985; 1: 134-140.

12. Stanescu D, Moavero NE, Veriter C, Brasseur L. Frequency dependence of respiratory resistance in healthy children. J Appl Physiol: Respirat Environ Exercise Physiol 1979; 47: 268-272. 
13. Williams SP, Fullton JM, Tsai MJ, Pimmel RL, Collier AM. Respiratory impedance and derived parameters in young children by forced random noise. J Appl Physiol 1979; 47: 169-174.

14. Wouters EFM. Total respiratory impedance measurement by forced oscillations: a noninvasive method to assess bronchial response in occupational medicine. Exp Lung Res 1990; 16: 25-40.

15. Pham QT, Bourgkard E, Chau N, et al. Forced oscillation technique (FOT): a new tool for epidemiology of occupational lung diseases? Eur Respir J 1995; 8: 1307-1313.

16. Cuijpers CEJ, Wesseling GJ, Swaen GMH, Wouters EFM. Frequency dependence of oscillatory resistance in healthy primary school children. Respiration 1993; 60: 149-154.

17. Cuijpers CEJ, Wesseling GJ, Swaen GMH, Sturmans F, Wouters EFM. Asthma related symptoms and lung function in primary school children. J Asthma 1994; 31 : 301-312.

18. Woestijne van de KP, Desager KN, Duiverman EJ, Marchal F. Recommendations for measurement of the respiratory input impedance by means of the forced oscillation method. Eur Respir Rev 1994; 4: 235237.

19. Florey C du V, Leeder SR. Methods for cohort studies of chronic airflow limitation. Chapter 3. WHO regional publications, European series No. 12, London, UK, 1982.

20. Brunekreef B, Groot B, Rijcken B, Hoek G, Steenbekkers A, Boer de A. Reproducibility of childhood respiratory symptom questions. Eur Respir J 1992; 5: 930-935.
21. Làndsér FJ, Nagels J, Demedts M, Billiet L, Woestijne van de KP. A new method to determine frequency characteristics of the respiratory system. J Appl Physiol 1976; 41: 101-106.

22. Wouters EFM, Làndsér FJ, Polko AH, Visser BF. Physiological analysis of extended spectrum oscillometry. Respiration 1988; 54: 263-270.

23. Peslin R, Duvivier C, Gallina C, Cervantes P. Upper airway artifact in respiratory impedance measurements. Am Rev Respir Dis 1985; 132: 712-714.

24. Làndsér FJ, Nagels J, Clément J, Woestijne van de KP. Errors in the measurement of total respiratory resistance and reactance by forced oscillations. Respir Physiol 1976; 28: 289-301.

25. Metz CE. Basic principles of ROC analysis. Semin Nucl Med 1978; Vol. VIII (4): 283-299.

26. SPSS ${ }^{\circledR}$ Inc., $444 n$ Michigan Avenue, Chicago, Illinois 60611, 1990.

27. Buhr W, Reimnitz P, Jörres R, Berdel D. Sensitivity and specificity of polyfrequent oscillation method, body plethysmography and spirometry in asthmatics aged 5 to 8 years. Pneumology 1990; 40: 1196-1198.

28. Duiverman EJ, Neijens HJ, Strik van R, van der SneeSmaalen M, Kerrebijn KF. Bronchial responsiveness in asthmatic children aged 3 to 8 years measured by the forced pseudorandom noise oscillometry. Bull Eur Physiopathol Respir 1986; 22: 27-34.

29. Duiverman EJ, Neijens HJ, van der Snee-Smaalen M, Kerrebijn KF. Comparison of forced oscillometry and forced expirations for measuring dose-related responses to inhaled methacholine in asthmatic children. Bull Eur Physiopathol Respir 1986; 22: 433-436. 